\title{
Preparation and Evaluation of Hydrogel Nanoparticles as Drug Delivery System
}

Rajveer Kaur ${ }^{1}$, Vishal Kumar Gupta² and Suresh Chandra Pandey²*

${ }^{1}$ Punjab University, Chandigarh, Punjab, India

${ }^{2}$ Department of Pharmaceutics, JSS College of Pharmacy, JSS University, S.S Nagar Mysore, Karnataka, India

\begin{abstract}
Hydrogel nanoparticles (NPs) can be used for colon drug delivery, utilizing Methotrexate (MTX) as a model drug . MTX loaded hydrogel NPs were prepared using Poly-acrylamide-grafted- gum ghatti (PAAm-g-Gg), which is $\mathrm{pH}$ sensitive. PAAm-g-Gg was synthesized by free radical polymerization. MTX loaded hydrogel NPs was prepared from PAAm-g-Gg by using nanoemulsification polymer crosslinking method. FT-IR and DSC studies of the prepared NPs indicated no chemical change of MTX in the hydrogel NPs. The prepared hydrogel NPs showed mean diameters in the range of $238 \pm 0.57 \mathrm{~nm}$ to $1064 \pm 0.99 \mathrm{~nm}$. The encapsulation efficiency of the drug was found to be $39.11 \%$ to $48.84 \%$. The suitability of the polyacrylamide grafted gum ghatti hydrogel NPs for the release of Methotrexate was studied by in vitro release at $\mathrm{pH} 1.2$ and 7.4. It was observed that, there was no significant amount of drug release in gastric $\mathrm{pH}$ and $97.28 \%$ of drug release at $\mathrm{pH} 7.4$ for formulation $\mathrm{F} 6$ at the end of $12 \mathrm{hrs}$. Based on result formulation $\mathrm{F} 6$ was considered as the best formulation and further evaluated for stability studies and characterized for surface morphology using SEM. SEM photographs have shown that the hydrogel NPs are spherical in shape and the stability study data indicated no significant change in the drug content.
\end{abstract}

Keywords: Hydrogel nanoparticles; PAAm-g-Gg; Colon drug delivery; Methotrexate

\section{Purpose}

The oral route is considered to be most convenient for administration of drugs to patients. Oral administration of conventional dosage forms normally dissolves in the stomach fluid or intestinal fluid and absorb from these regions of the GIT depends upon the physicochemical properties of the drug.

It is a serious drawback in conditions where localized delivery of the drugs in the colon is required or in conditions where a drug needs to be protected from the hostile environment of upper GIT. Dosage forms that deliver drugs into the colon rather than upper GIT proffers number of advantages.

The advantages of colon targeted delivery is to improve the efficacy by concentrating the drug molecule where they need, minimize the potential side effects, premature release of drug in upper part of GIT, minimize the dosing and prolong the drug delivery.

- There is lot of difference in $\mathrm{pH}$ of stomach and colon, so by the use of biodegradable $\mathrm{pH}$ sensitive polymers for colon-specific drug delivery seems to be a more site-specific approach in which drug release is triggered by $\mathrm{pH}$ sensitive polymer coatings.

- Hence there is a need to develop hydrogel NPs with controllable releasing function that decreased not only the degradation but the nonspecific release of drug molecules in the gastrointestinal tract (GIT)

- In the present study an attempt has made to develop hydrogel NPs for colon targeted drug delivery system employing polyacrylamide grafted gum ghatti as $\mathrm{pH}$ sensitive polymer.

\section{Introduction}

Cancer is undoubtedly a serious and potentially life threatening illness. Cancer of the colon and rectum is one of the most common internal malignancies. The majority of the people with colorectal cancer are over the age of 50. Dietary factors such as low folate intake are thought to increase the risk of colorectal cancer by 2 to 5 time [1,2]. However, it is a misconception to think that all forms of cancer are untreatable and deadly.

Conventional chemotherapeutic drug leads to nonspecific drug delivery by which it affects not only cancerous cells but also healthy cells, which leads to complications like dose related side effects, occurrence of resistance and inadequate drug concentration reaching tumor which leads to decrease in efficacy of chemotheraphy [3-5]. NPs are considered one of the most promising dosage forms as potential formulation for site specific drug delivery system including drug targeting.

Oral ingestion is the most convenient and commonly employed route of drug delivery [6]. Though the low bioavailability and short biological half-life of drug for the oral administration favors the developments of a controlled release formulation [7]. Targeted drug delivery to the colon would therefore ensure direct treatment at the disease site, lower dosing and fewer systemic side effects. In recent times, colon targeted drug delivery system have gained importance for the systemic delivery of protein and peptide drugs [8]. Targeting of the drugs to the colon via the oral route can be achieved by different approaches including different formulation systems, for which the drug release is controlled by different $\mathrm{pH}$ conditions, transit time and intestinal microbial flora. MTX is one of the most effective anticancer agents available clinically. It has a spectrum of activity against solid tumor, including colon cancer.

*Corresponding author: Suresh Chandra Pandey, Department of Pharmaceutics JSS College of Pharmacy, JSS University, S.S Nagar, Mysore, India, Tel: 919015011137; E-mail: sureshpandey157@gmail.com

Received: January 18, 2019; Accepted: February 22, 2019; Published: February 28, 2019

Citation: Kaur R, Gupta VK, Pandey SC (2019) Preparation and Evaluation of Hydrogel Nanoparticles as Drug Delivery System. J Nanomed Nanotechnol 10: 526 doi: 10.4172/2157-7439.1000526

Copyright: (c) 2019 Pandey SC. This is an open-access article distributed under the terms of the Creative Commons Attribution License, which permits unrestricted use, distribution, and reproduction in any medium, provided the original author and source are credited. 
Citation: Kaur R, Gupta VK, Pandey SC (2019) Preparation and Evaluation of Hydrogel Nanoparticles as Drug Delivery System. J Nanomed Nanotechnol 10: 526. doi: 10.4172/2157-7439.1000526

Page 2 of 7

In addition, Polysaccharides the polymer of monosaccharides, retain their integrity in the upper gastrointestinal tract because they are resistant to the digestive action of gastrointestinal enzyme $[9,10]$. Another favorable property of these materials is that they have already been approved as pharmaceutical excipient. Gum ghatti is a water soluble complex polysaccharide exuded from the bark of the tree Anogeissus latifolia of the family Combretaceae [11]. These are polysaccharides, the polymer of monosaccharides, retain their integrity in upper GIT. The polymer was synthesized by free radical polymerization were acryl amide (AAm) and potassium persulfate used for Synthesis of PAAmg-Gg Copolyme. During alkaline hydrolysis, $-\mathrm{CONH}_{2}$ group of PAAm present on the backbone of $\mathrm{Gg}$ are converted to - $\mathrm{COOH}$ group resulting $\mathrm{pH}$ sensitive polymer. This natural polymer having large number of derivatizable group, a wide range of molecular weight varying chemical composition, low toxicity and high stability. MTX loaded NPs were prepared by nanoemulsification polymer cross-linking method.

Gum ghatti is hydrophilic and swells in cold water, forming viscous colloidal dispersion or sols. This gelling property retards release of the drug from the dosage forms, making it more likely that degradation will occur in the colon, Gum ghatti was also found to be a colon specific drug carrier in the form of matrix and compression coated tablets as well as microspheres $[12,13]$

Several studies have been carried out to prepare NPs as a drug delivery system for treatment of cancer. NPs containing Adriamycin prepared by using biocompatible poly (lactide-co-glycolide)polyethylene glycol (PLGA-PEG) polymers. The method used was precipitation-solvent evaporation and prepared Particle sizes between 65 and $100 \mathrm{~nm}$ for different compositions of PLGA-PEG copolymers. Entrapment efficiency was $25 \%-33 \%$. Adriamycin release from the NPs at $\mathrm{pH} 7.4$ showed an initial burst release and then sustained release phase. These results showed that PLGA-PEG NPs could be an effective carrier for cancer therapy [14].

Methotrexate (MTX)-encapsulated polymeric NPs using methoxy poly (ethylene glycol) (MPEG)-grafted chitosan (ChitoPEG) copolymer were also prepared. The size was around $50-300 \mathrm{~nm}$ and showed spherical shape when observed by transmission electron microscope. Study of NMR indicated that MTX/chitosan complexes composed of inner-core and MPEG composed of outer-shell of the NPs. Loading efficiency of MTX in the polymeric nanoparticles was $94 \%(\mathrm{w} / \mathrm{w})$ of ChitoPEG-1, 91.1\% (w/w) of ChitoPEG-2, 90.1\% (w/w) of ChitoPEG-3 and $65.2 \%(\mathrm{w} / \mathrm{w})$ of ChitoPEG-4. Higher the drug feeding ratio, higher is the drug content and lower the loading efficiency [15].

Modified spontaneous emulsification method used to prepare chitosan nanospheres containing Doxorubicin hydrochloride. Useful prodrugs were produced through Chemical attachment of drug to chitosan, exhibiting increased biological activity at target site by mucoadhesive and absorption enhancement properties of chitosan. The results suggest that doxorubicin (DOX) was unable to penetrate into cells and did not effectively inhibit cell proliferation. In contrast, NPs can penetrate into cells and effectively inhibit cell proliferation [16]. To our best knowledge no study has been carried to investigate inexpensive, natural and abundantly (100-2500 nm also called fine particles) for colon targeted delivery of MTX. The present research focused on the development and available gum ghatti NPs characterization of novel gum ghatti hydrogel NPs for colon-targeted delivery of MTX.

\section{Materials}

Methotrexate BP (Cipla limited Mumbai, India), Gum Ghatti (laba chem. Mumbai. India), Acrylamide (Laba Chem, Mumbai, India),
Span80 (Laba Chem, Mumbai, India), PVA (Laba Chem, Mumbai, India), Glutaldehyde (Laba Chem, Mumbai, India), Hydrochloric acid (Reachem Mumbai, India), Sodium hydroxide (Reachem Mumbai, India).

\section{Reagents}

Sodium hydroxide solution, Potassium dihydrogen phosphate, Hydrochloric acid

\section{Methods}

\section{Analytical methods}

Determination of lambda max of MTX in $\mathrm{pH} 1.2 \mathrm{HCl}$ buffer: UV visible scan range was taken between the wavelengths $200-400 \mathrm{~nm}$. By using UV visible spectrophotometer the spectrum was scanned and it give a peak at $304 \mathrm{~nm}$ and the same selected as lambda max for MTX and was used for further studies.

Determination of lambda max of MTX in $\mathrm{pH} 7.4$ phosphate buffer: UV visible scan range was taken between the wavelengths 200 $400 \mathrm{~nm}$. By using UV visible spectrophotometer the spectrum was scanned and it give a peak at $304 \mathrm{~nm}$ and the same selected as lambda max for MTX and was used for further studies (Figures 1 and 2).

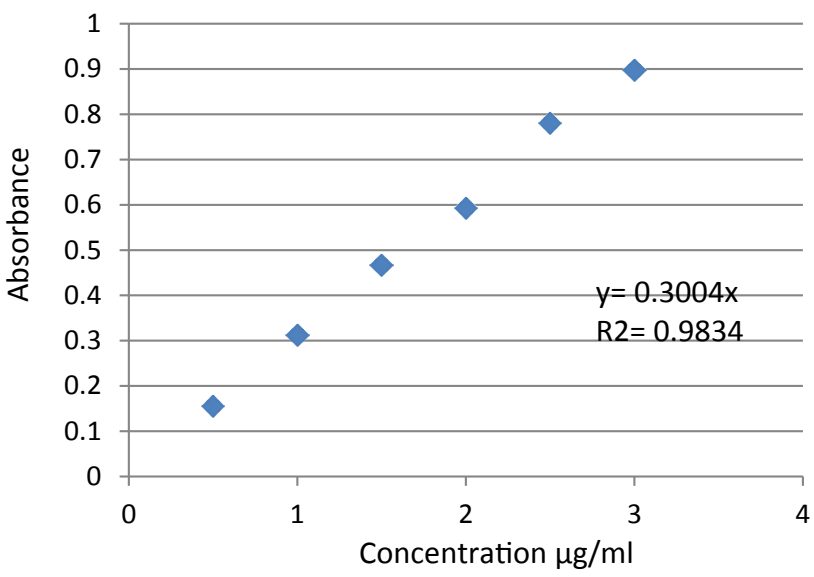

Figure 1: Standard plot of MTX in $\mathrm{pH} 1.2 \mathrm{HCl}$ buffer and $\mathrm{pH} 1.2 \mathrm{HCl}$ buffer

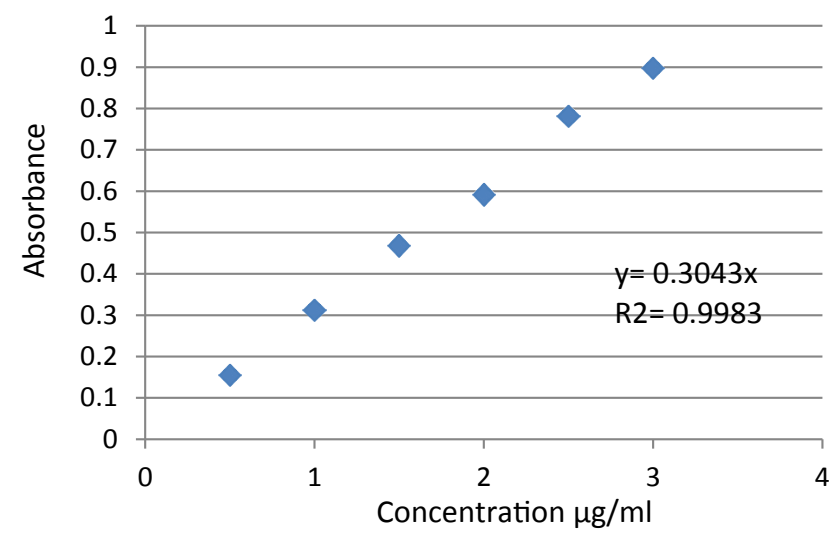

Figure 2: Standard plot of MTX in $\mathrm{pH} 1.2 \mathrm{HCl}$ buffer and $\mathrm{pH}$ 7.4 Phosphate buffer. 
Citation: Kaur R, Gupta VK, Pandey SC (2019) Preparation and Evaluation of Hydrogel Nanoparticles as Drug Delivery System. J Nanomed Nanotechnol 10: 526. doi: 10.4172/2157-7439.1000526

\section{Preparation of nanoparticles}

The process used to prepare Nanoemulsification polymer cross linking methods

Synthesis of PAAm-g-Gg copolymer: The polymer was synthesized by free radical polymerization. Two gm gum ghatti $(\mathrm{Gg})$ was dissolved in distilled water and allowed to hydrate for $4 \mathrm{hr}$. The flask was heated at $80^{\circ} \mathrm{C}, 0.8 \mathrm{~g}$ of acryl amide (AAm) and $0.5 \mathrm{~g}$ of potassium persulfate (KPS) were added to gum ghatti solution. Polymerization was carried out for $1 \mathrm{hr}$. The resulting polymer was allowed to cool at ambient temperature and the product was poured in excess methanol and kept for 24 hour to dewater. The polymer was then filtered, washed repeatedly with methanol, dried at $50^{\circ} \mathrm{C}$ overnight and finally kept in desiccators.

Alkaline hydrolysis of PAAm-g-Gg: Two gm of PPAm-g-Gg polymer was dissolved in $100 \mathrm{ml}$ of $0.9 \mathrm{M} \mathrm{NaOH}$ solution and stirred at $75^{\circ} \mathrm{C}$ for 60 minute in a thermostatic water bath, cooled and poured in to excess of methanol. Then the hydrolyzed polymer was separated by filtration and washed repeatedly with methanol and dried overnight at $50^{\circ} \mathrm{C}$.

Preparation of MTX nanoparticles: MTX loaded pH sensitive NPs were prepared by nonoemulsification polymer cross linking method using $\mathrm{pH}$ sensitive polymers PAAm-g-Gg.

Gum ghatti and poly vinyl alcohol NPs containing MTX were prepared by the nonoemulsion cross linking method. PVA was first dissolved in hot water at $80^{\circ} \mathrm{C}$ after cooling to ambient temperature; $\mathrm{Gg}$ was added and stirred overnight to get a homogenous solution. MTX was dissolved in $1 \mathrm{ml} 0.1 \mathrm{M} \mathrm{HCl}$ and then added to the mixture of gum ghatti and PVA and the solution was stirred to get a uniform solution. This solution was added to soyabean oil and $1 \% \mathrm{w} / \mathrm{w}$ span 80 and the mixture was rapidly stirred at very high rpm using Homogenizer model Polytron PT 1600E. Then 25\% glutaraldehyde solution was added slowly to affect cross linking. Nanosuspension was kept overnight for NPs formation. NPs were obtained after centrifugation at 20,000 rpm for 20 minute, washed with $15 \mathrm{ml}$ millipore water and recentrifuged. Finally the NPs were washed with $0.1 \mathrm{M}$ glycine solution to mask the untreated glutaradehyde and distilled water to remove the unreacted glutaraldehyde. The yielded NPs were lyophilized, harvested in micro centrifuge tubes and preserved in vacuum desiccator.

Effect of different process variables namely polymer concentration, crosslinker concentration, amount of emulsifier and amount of stabilizer were optimized to get NPs in the range of 200-800 nm. Initially PAAmg-Gg NPs of MTX are prepared by optimizing two different parameter such as concentration of PPAm-g-Gg $(0.5,1.0$ and $1.5 \% \mathrm{w} / \mathrm{v})$ and $25 \%$ glutaraldehyde concentration varied from 1.5 to $3.5 \% \mathrm{w} / \mathrm{w}$. The prepared PPAm-g-Gg NPs were fixed based on desired particle size and further optimized for span 80 and stabilizer concentration.

Formulation of design by factorial design: Factorial design is a computerized technique, by which the factors involved and its

\begin{tabular}{|c|c|c|c|c|c|c|}
\hline \multirow{2}{*}{ Factor } & \multicolumn{3}{|c|}{ Coded values } & \multicolumn{3}{c|}{ Actual values } \\
\cline { 2 - 7 } & $\begin{array}{c}\text { Low } \\
\text { level }\end{array}$ & $\begin{array}{c}\text { Mid- } \\
\text { level }\end{array}$ & $\begin{array}{c}\text { High } \\
\text { level }\end{array}$ & $\begin{array}{c}\text { Low } \\
\text { lever }\end{array}$ & $\begin{array}{c}\text { Mid- } \\
\text { level }\end{array}$ & $\begin{array}{c}\text { High } \\
\text { level }\end{array}$ \\
\hline $\begin{array}{c}\text { Factor A } \\
\text { PAAm-g-Gg }\end{array}$ & -1 & 0 & +1 & 1. & 2 & 2.5 \\
\hline $\begin{array}{c}\text { Factor B } \\
\text { PVA }\end{array}$ & -1 & 0 & +1 & 1.5 & 3.25 & 5.0 \\
\hline $\begin{array}{c}\text { Factor C } \\
\text { Glutaraldehyde }\end{array}$ & -1 & 0 & +1 & 1.5 & 2.5 & 3.5 \\
\hline
\end{tabular}

Table 1: Actual and coded levels of the factors. relative importance can be assessed by adopted for formulation of hydrogel NPs. $2^{3}$ a full factorial design were employed. The amount of Gum ghatti, PVA and glutraldehyde were selected as the factors studied (Tables 1 and 2).

\section{Result and Discussion}

The present study was carried out to formulate the hydrogel NPs containing MTX as colon targeted drug delivery.

MTX loaded hydrogel NPs were prepared by nonoemulsification polymer crosslinking method using natural $\mathrm{pH}$ sensitive polymer gum ghatti in a grafted form with polyacylamide (PAA-g-Gg), which possess physical properties and behavior suitable to prepare gastro resistant and biocompatible hydrogel NPs to release the entrapped drug in the colon.

\begin{tabular}{|c|c|c|c|c|c|c|}
\hline \multirow{2}{*}{ FC } & \multicolumn{3}{|c|}{ Actual value } & \multicolumn{3}{c|}{ Coded value } \\
\cline { 2 - 7 } & PAAm-g-Gg & PVA & Glutaraldehyde & PAAm-g-Gg & PVA & Glutaraldehyde \\
\hline F1 & 2.5 & 1.5 & 3.5 & 1 & -1 & 1 \\
\hline F2 & 2.5 & 5 & 3.5 & 1 & 1 & 1 \\
\hline F3 & 2.0 & 3.25 & 2.5 & 0 & 0 & 0 \\
\hline F4 & 1.5 & 1.5 & 1.5 & -1 & -1 & -1 \\
\hline F5 & 1.5 & 5 & 1.5 & -1 & 1 & -1 \\
\hline F6 & 2.5 & 1.5 & 1.5 & 1 & -1 & -1 \\
\hline F7 & 1.5 & 5 & 3.5 & -1 & 1 & 1 \\
\hline F8 & 1.5 & 1.5 & 3.5 & -1 & -1 & 1 \\
\hline F9 & 2.5 & 5 & 3.5 & 1 & 1 & -1 \\
\hline
\end{tabular}

Table 2: Factorial design in coded and actual values.

\begin{tabular}{|c|c|c|c|c|c|c|}
\hline Formulation & $\begin{array}{c}\text { PAAm-g- } \\
\text { Gg } \mathbf{\%} \mathbf{w} / \mathbf{v}\end{array}$ & $\begin{array}{c}\text { PVA } \\
\mathbf{\%} \mathbf{w} / \mathbf{v}\end{array}$ & $\begin{array}{c}\text { Oil in } \\
\mathbf{m l}\end{array}$ & $\begin{array}{c}\text { Span } \mathbf{8 0} \\
\mathbf{1} \% \mathbf{w} / \mathbf{w}\end{array}$ & $\begin{array}{c}\text { Drug in } \\
\mathbf{m g}\end{array}$ & $\begin{array}{c}\text { Glutaraldehyde } \\
\mathbf{~ m l}\end{array}$ \\
\hline F1 & 2.0 & 5.0 & 10 & 4 & 25 & 3.5 \\
\hline F2 & 1.5 & 1.5 & 10 & 4 & 25 & 3.5 \\
\hline F3 & 1.5 & 1.5 & 10 & 4 & 25 & 1.5 \\
\hline FF4 & 1.5 & 5.0 & 10 & 4 & 25 & 3.5 \\
\hline F5 & 2.0 & 3.25 & 10 & 4 & 25 & 2.5 \\
\hline F6 & 2.5 & 1.5 & 10 & 4 & 25 & 3.5 \\
\hline F7 & 2.5 & 5.0 & 10 & 4 & 25 & 1.5 \\
\hline F8 & 1.5 & 5.0 & 10 & 4 & 25 & 1.5 \\
\hline F9 & 2.5 & 1.5 & 10 & 4 & 25 & 1.5 \\
\hline
\end{tabular}

Table 3: Formulation chart of MTX loaded PAAm-g-Gg NPs by DOE.

To encapsulate MTX, PAAm-g-Gg was used as polymer; PVA was used as hydrophilic polymer, span 80 as an emulsifier and glutaraldehyde as crosslinking agents (Table 3).

The PAAm-g-Gg was synthesized by free radical polymerization under the nitrogen atmosphere followed by alkaline hydrolysis to obtained $\mathrm{pH}$ sensitive polymer. During alkaline hydrolysis, $-\mathrm{CONH}$ group of PAAm present on the backbone of $\mathrm{Gg}$ are converted to $\mathrm{COOH}$ group resulting $\mathrm{pH}$ sensitive polymer.

Span 80 act as helping agents for transfer of MTX to PAAm-g-Gg during controlled evaporation of the solvent. The low HLB value of span 80 help in transfer of MTX to PAAm-g-Gg rather than water. Higher HLB value of the emulsifier will hinder detachment of MTX from the solvent and transfer to PAAm-g-Gg. Hence span 80 is producing the right balance in changing weak interactive forces in the process. Span 80 also performs the role of an antifoaming agent apart from being an emulsifier.

Glutaraldehyde is a bifunctional cross linker with two aldehyde group at both ends. Glutaraldehyde causes cross linking with the active 
Citation: Kaur R, Gupta VK, Pandey SC (2019) Preparation and Evaluation of Hydrogel Nanoparticles as Drug Delivery System. J Nanomed Nanotechnol 10: 526. doi: 10.4172/2157-7439.1000526

Page 4 of 7

primary hydroxylic group of the PAAm-g-Gg by H-bonding, interfering with the presence of water to the hydroxyl group of PAAm-g-Gg.

The design of formulation with a set of process variables for preparation of MTX loaded hydrogel NPs was constructed. Effect of different process variable namely rate of addition of polymeric solution to cross linking solution, homogenization speed and duration. Important factors that influence the size distribution of NPs are the optimum homogenization speed and time.

A homogenization speed of 20,000 rpm and duration of $20 \mathrm{~min}$ was maintained to obtain reproducible NPs. It was observed that with the increase in the homogenization speed from 20000-25000 rpm, there was a decrease in the recovery yield of the NPs and the formed NPs tend to fuse. When the stirring speed was lower than $20000 \mathrm{rpm}$, particles size range was large and resultant NPs were composed of irregular masses, which were not possible to distinguish individual NPs. When the stirring time was lower than $20 \mathrm{~min}$, it was observed that some amount of the dissolved mass adhered to the inner sides of the beaker, resulting in lower percentage yield (Table 4).

From the above results, Homogenization duration 20 min was considered as optimum as it produced a good yield of NPs. Injection rate of the polymer solution was optimized to prevent aggregation of hydrogel NPs. The rate higher than $1 \mathrm{~min} / \mathrm{min}$ of polymer drug solution to crosslinking solution resulted in a greater particles size with partial aggregation. Formulation F1 (D4) showed better yield when compared to other formulation (Table 5).

\section{Characterization}

Particles size: The MTX loaded hydrogel NPs were characterized for particles size by using particles size analyzer. By using clear disposable zeta cell, water as a dispersant which has RI-1.330 and viscosity $(\mathrm{cP})-0.8878$ and at a temperature of $25^{\circ} \mathrm{C}$ for duration of 60 sec and the results are shown in the figure. Various ratios of PPA-gGg, PVA and glutaraldehyde were tested to optimize the fabrication procedure of NPs. The mean diameter of formulation F6 was found to be $272 \mathrm{~nm}$, while the other formulation was in the range of 2381064 nm Figure 3.

Zeta potential: Zeta potential is the potential difference of the dispersion medium and stationary layer of fluid attached to the dispersed particles. The zeta potential indicates the degree of repulsion between adjacent, similarly charged particles in dispersion. For molecules and particles that are small enough, a high zeta potential will confer stability, i.e. the solution of dispersion will resist aggregation (Figure 4).

\begin{tabular}{|c|c|c|}
\hline Trial Batch No & Time in min & \% Yield \\
\hline F1 (D1) & 5 & 37.15 \\
\hline F1 (D2) & 10 & 48.37 \\
\hline F1 (D3) & 15 & 65.23 \\
\hline F1 (D4) & $\mathbf{2 0}$ & $\mathbf{7 2 . 8 0}$ \\
\hline F1 (D5) & 25 & 62.89 \\
\hline F1 (D6) & 30 & 46.46 \\
\hline F1 (D7) & 35 & 40.56 \\
\hline
\end{tabular}

Table 4: Effect of duration of homogenization on percentage yield of MTX loaded hydrogel NPs.

\begin{tabular}{|c|c|}
\hline Process parameter & Optimized values \\
\hline Homogenization speed & $20000 \mathrm{rpm}$ \\
\hline Homogenization Time & $20 \mathrm{~min}$ \\
\hline Rate of injection of polymer-drug solution & $1 \mathrm{ml} / \mathrm{min}$ \\
\hline
\end{tabular}

Table 5: Process parameter and optimized value.
Hydrogel NPs zeta potential mainly depends on the chemical nature of the polymer, the chemical nature of the stabilizing agent and $\mathrm{pH}$ of the medium. Therefore when hydrogel NPs are prepared from acrylamide derivation using non-ionic polymer, negative zeta potential values are obtained due to the presence of polymer terminal carboxylic group. It was absorbed that prepared hydrogel NPs have sufficient charge to inhibit aggregation.

Polydispersity index (PDI): The PDI is a parameter used to define the particles size distribution of NPs; it is a dimensionless number and range from a value of 0.01 for monodispersed particles up to value of around 0.5-0.7. Values greater than 0.7 are characteristic of sample with a broad size distribution.

PDI of the formulation F6 was found to be less than 0.5 indicating narrow particles size ranges as show in the Figure 5.

Scanning electron microscopy analysis (SEM): Surface morphology of formulation F6 was carried out using SEM (JSM-840 A scanning microscopy, Tokyo Japan).

NPs did not have porous surface in acidic $\mathrm{pH}$, suggesting that the drug release in minimum is acidic $\mathrm{pH}(\mathrm{pH} 1.2)$. The surface morphology of hydrogel NPs exposed in alkaline $\mathrm{pH}(\mathrm{pH} 7.4)$ revealed highly porous

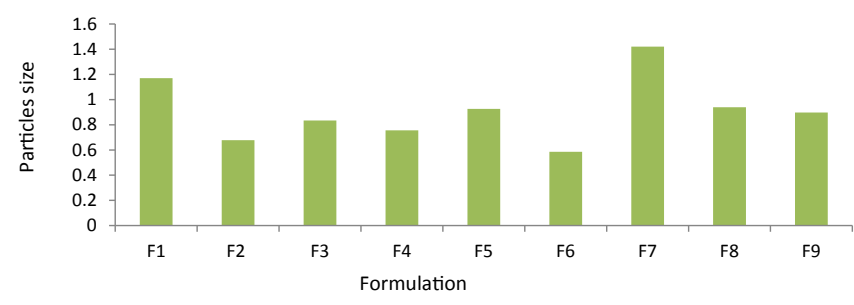

Figure 3: Column graph showing particles size of NPs.

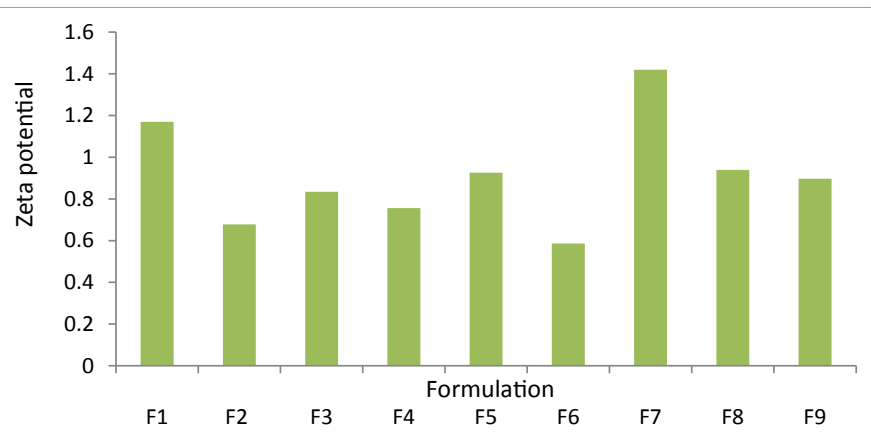

Figure 4: Column graph showing Zeta-potential of NPs.

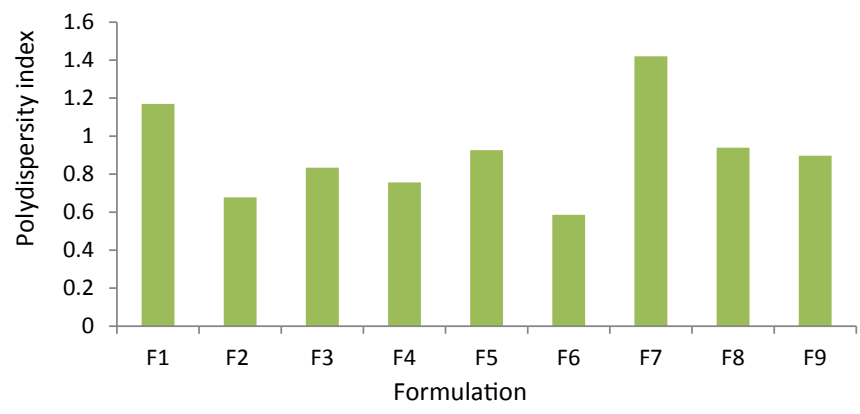

Figure 5: Column graph showing Polydispersity index of hydrogel nanoparticles. 
Citation: Kaur R, Gupta VK, Pandey SC (2019) Preparation and Evaluation of Hydrogel Nanoparticles as Drug Delivery System. J Nanomed Nanotechnol 10: 526. doi: 10.4172/2157-7439.1000526

Page 5 of 7

matrix, thus the $\mathrm{pH}$ dependent swelling behavior was confirmed by examining the surface morphology of hydrogel NPs exposed to acidic and alkaline $\mathrm{pH}$ using SEM (Figure 6).

Differential scanning calorimeter: In order to study any possible interaction between the drug and polymers, DSC studies were carried out. The DSC thermo grams obtained are reported in the Figure 7 and Table 6.

FT-IR analysis: MTX pure drug and the optimized formulation by particle size and drug release were subjected for FT-IR spectroscopic analysis for compatibility studies and to ascertain whether there was no interaction between the drug and polymer used (Table 7).

It was observed that there was no disappearance or significant shift in the peak position of drug in any spectra of drug with formulation, which provide that the drug and polymer used for study were compatible.

Drug loading/encapsulation efficiency: Formulation was evaluated for encapsulation efficiency and drug loading. Encapsulation efficiency and drug loading were determined as the method. The results obtained are given in the Figure 8.

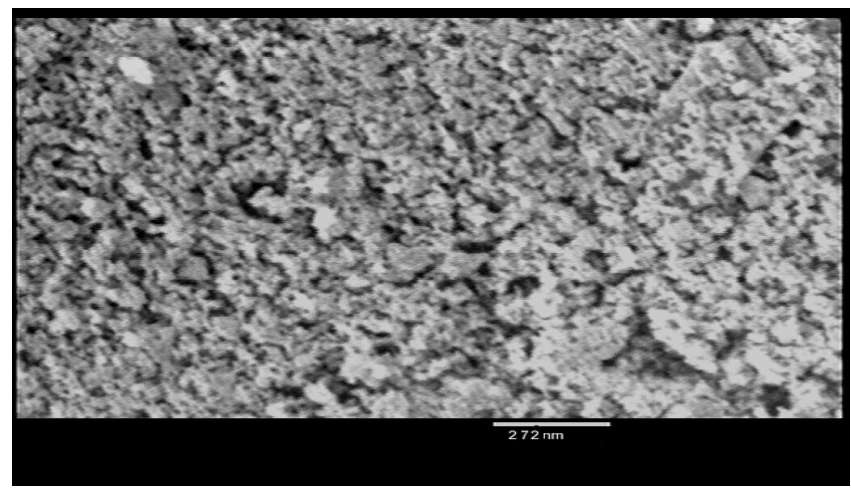

Figure 6: SEM of Pure MTX \& Formulation F6.

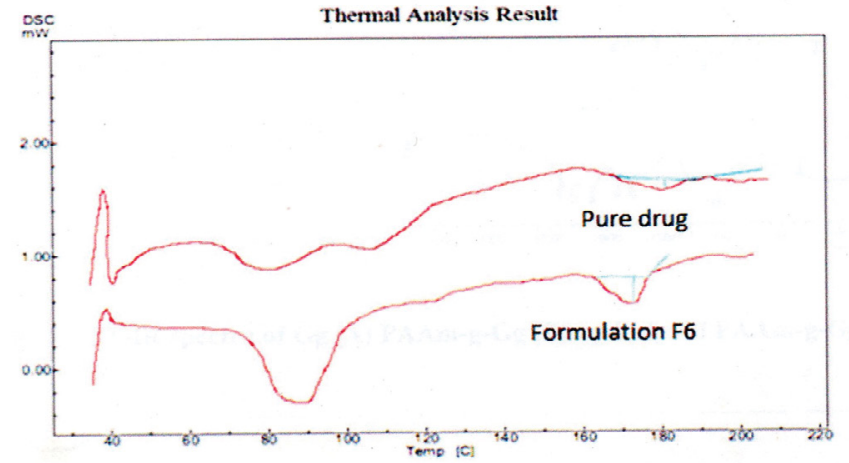

Figure 7: DSC of Pure MTX \& Formulation F6.

\begin{tabular}{|c|c|c|c|c|c|}
\hline S. No & Sample & $\mathbf{T}^{\circ}\left({ }^{\circ} \mathbf{C}\right)$ & $\mathbf{T}^{\mathbf{m}}\left({ }^{\circ} \mathbf{C}\right)$ & $\mathbf{T}^{\mathbf{e}}\left({ }^{\circ} \mathbf{C}\right)$ & Melting range $\left({ }^{\circ} \mathbf{C}\right)$ \\
\hline 1 & MTX & 172.85 & 181.58 & 191.12 & 18.27 \\
\hline 2 & F6 & 162.48 & 176.65 & 179.23 & 16.75 \\
\hline
\end{tabular}

$\mathrm{T}^{\mathrm{0}}$-Onset of melt, $\mathrm{T}^{\mathrm{m}}$-Melting point, $\mathrm{T}^{\mathrm{e}}$-Completion of melt

Table 6: DSC data of MTX and formulation F6.

\begin{tabular}{|c|c|c|}
\hline Functional group & $\begin{array}{c}\text { Frequency of the } \\
\text { pure drug } \\
\text { (in cm-1) }\end{array}$ & $\begin{array}{c}\text { Frequency of the } \\
\text { formulation } \\
\text { (in cm } \text { cm}^{-1} \text { ) }\end{array}$ \\
\hline NH stretching & $3365 \mathrm{~cm}^{-1}$ & $3346 \mathrm{~cm}^{-1}$ \\
\hline Aromatic $\mathrm{CH}$ stretching & $2958 \mathrm{~cm}^{-1}$ & $2927 \mathrm{~cm}^{-1}$ \\
\hline $\mathrm{C}=\mathrm{O}$ stretching & $1645 \mathrm{~cm}^{-1}$ & $1644 \mathrm{~cm}^{-1}$ \\
\hline $\mathrm{C}=\mathrm{C}$ stretching & $1498 \mathrm{~cm}^{-1}$ & $1512 \mathrm{~cm}^{-1}$ \\
\hline $\mathrm{C}=\mathrm{N}$ stretching & $1207 \mathrm{~cm}^{-1}$ & $1206 \mathrm{~cm}^{-1}$ \\
\hline
\end{tabular}

Table 7: FT-IR peaks of MTX and formulation.

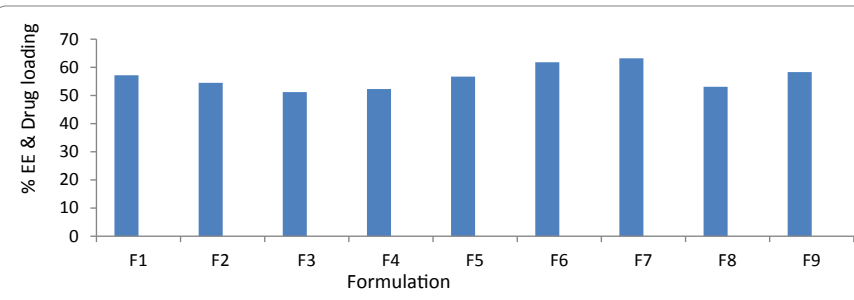

Figure 8: Column graph showing drug loading and EE of Hydrogel NPs.

Encapsulation efficiency was calculated using formula

$\% \mathrm{EE}=[($ Drug added - Free "unentrapped drug" $) /$ Drug added $] \times 100$

The encapsulation efficiency and drug loading was found to increase with increase in the polymer concentration. The encapsulation efficiency was found to be $38.23 \%$ to $48.84 \%$ and percentage drug loading was in range of $16.65 \%$ to $24.69 \%$ for the prepared formulations.

There are many factors that can influence the encapsulation efficiency and loading efficiency. For example modifying the dispersed or dispersing phase of the emulsion/stabilizer to reduce the leakage of the drug molecule from the droplets can thus make improvement of the encapsulation efficiency of the drug hydrogel NPs.

Percentage yield: The hydrogel NPs from each formulation were weight and the respective yield was calculated using the following formula:

Percentage yield $=\mathrm{Wt}$ of hydrogel NPs obtained $/ \mathrm{Wt}$ of drug and polymer used $\times 100$

It was observed that percentage yield of hydrogel NPs increases proportionally by increasing the concentration of polymer, illustrated in the Figure 8.

The percentage yield may not be $100 \%$ due to the loss in final product, because of the mechanical variables employed in the preparation of hydrogel NPs, hence, they are weight after drying and yield was calculated as show in the Figure 9.

In vitro release: The release profile of the MTX from hydrogel NPs were evaluated at simulated gastric fluid $\mathrm{pH}(1.2)$ and simulated intestinal fluid $\mathrm{pH}$ (7.4). The release rate of drug distinctively increased as $\mathrm{pH}$ of the fluid changed from 1.2 to 7.4 at which NPs quickly dissolved, achieving $97.24 \%$ of the release amount of the loaded MTX at the end of $12 \mathrm{hrs}$. These results indicated that MTX was retained by hydrogel NPs at acidic $\mathrm{pH}$, but they were rapidly released from hydrogel NPs at alkaline $\mathrm{pH}$. The results of this study clearly supported that polyacrylamide grafted Gum ghatti hydrogel NPs can be used as colon targeted drug delivery system (Table 8 and Figure 10).

Cumulative percentage release $(\%)=$ Volume of sample withdrawn $(\mathrm{ml}) /$ bath volume $(\mathrm{v}) \times \mathrm{P}(\mathrm{t}-1)+\mathrm{Pt}$ 
Citation: Kaur R, Gupta VK, Pandey SC (2019) Preparation and Evaluation of Hydrogel Nanoparticles as Drug Delivery System. J Nanomed Nanotechnol 10: 526. doi: 10.4172/2157-7439.1000526

Page 6 of 7

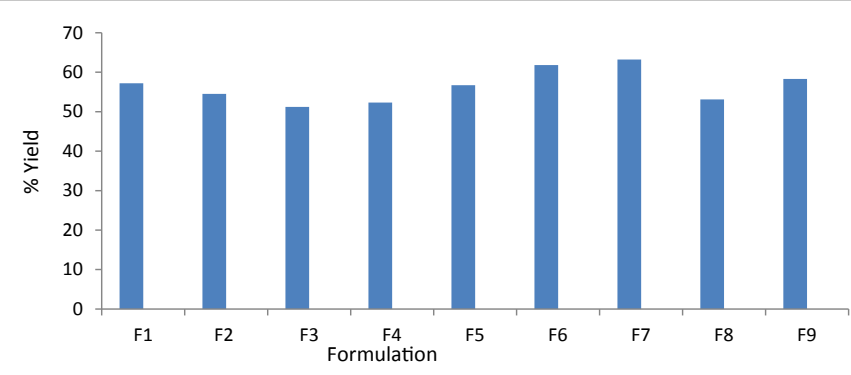

Figure 9: Column graph showing drug Percentage yield of hydrogel NPs.

\begin{tabular}{|c|c|c|c|c|c|c|c|c|c|}
\hline \multirow{2}{*}{$\begin{array}{l}\text { Time } \\
\text { (Hrs) }\end{array}$} & \multicolumn{9}{|c|}{ Cumulative $\%$ drug release mean $\pm S^{*}$} \\
\hline & F1 & F2 & F3 & F4 & F5 & F6 & F7 & F8 & F9 \\
\hline & \multicolumn{9}{|c|}{ pH 1.2} \\
\hline 0 & 0 & 0 & 0 & 0 & 0 & 0 & 0 & 0 & 0 \\
\hline 1 & 1.93 & 1.39 & 1.62 & 1.69 & 1.49 & 2.13 & 1.47 & 1.43 & 2.13 \\
\hline \multirow[t]{2}{*}{2} & 4.89 & 2.88 & 2.38 & 5.97 & 6.28 & 3.94 & 2.75 & 2.29 & 2.89 \\
\hline & \multicolumn{9}{|c|}{ pH 7.4} \\
\hline 3 & 17.69 & 8.17 & 7.92 & 13.29 & 15.63 & 10.92 & 12.38 & 11.37 & 9.01 \\
\hline 4 & 29.49 & 17.73 & 11.98 & 25.37 & 23.45 & 26.67 & 26.13 & 24.53 & 13.21 \\
\hline 5 & 33.85 & 25.47 & 19.65 & 32.89 & 33.95 & 37.31 & 29.69 & 30.69 & 23.26 \\
\hline 6 & 41.73 & 34.94 & 27.47 & 39.41 & 40.33 & 42.27 & 37.93 & 38.29 & 30.57 \\
\hline 7 & 46.67 & 49.64 & 34.29 & 45.67 & 48.72 & 47.78 & 45.23 & 49.18 & 39.38 \\
\hline 8 & 59.48 & 57.81 & 43.87 & 58.91 & 56.19 & 62.36 & 51.85 & 60.22 & 47.87 \\
\hline 9 & 68.97 & 65.34 & 54.73 & 67.58 & 66.58 & 70.53 & 68.12 & 66.72 & 58.43 \\
\hline 10 & 74.87 & 72.11 & 69.33 & 73.13 & 71.92 & 77.38 & 76.72 & 78.89 & 66.67 \\
\hline 11 & 87.12 & 83.65 & 72.48 & 86.79 & 83.86 & 88.98 & 82.87 & 85.78 & 75.89 \\
\hline 12 & 95.86 & 89.57 & 82.23 & 91.38 & 87.67 & 97.28 & 86.72 & 86.27 & 84.19 \\
\hline
\end{tabular}

Table 8: In vitro release data of prepared hydrogel NPs Formulation.

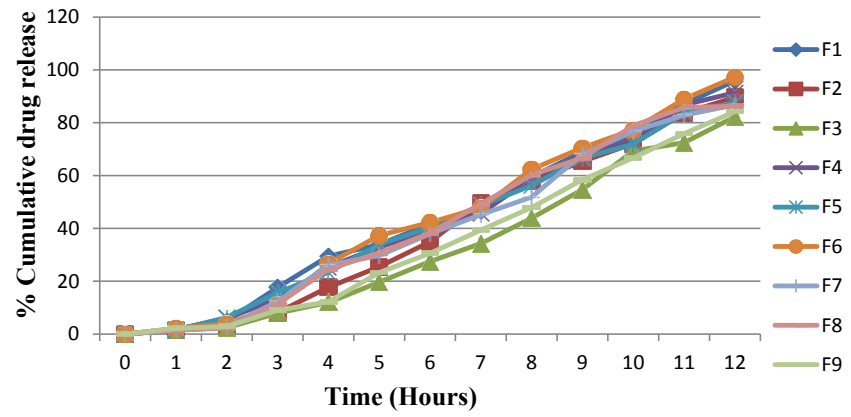

Figure 10: Graph showing In vitro release of NPs formulation.

Where $\mathrm{Pt}=$ Percentage release at time $\mathrm{t}$ and $\mathrm{P}(\mathrm{t}-1)=$ Percentage release previous to ' $\mathrm{t}$ '

\section{Mathematical model fitting of obtained release data}

In order to describe the kinetics of the release of the drug in all formulations, various equations were used such as zero order rate equation, first order equation, Higuchi equation and Korsmeyer peppas equation (Table 9).

The in vitro release data was fitted in to various mathematical models to determine which the best fit model was. For the formulation

\begin{tabular}{|c|c|c|c|c|c|c|}
\hline \multirow[b]{2}{*}{ Formulation } & \multicolumn{4}{|c|}{$\mathbf{R}^{2}$ Values } & \multirow[b]{2}{*}{ 'n' Value } & \multirow{2}{*}{$\begin{array}{l}\text { Best fit } \\
\text { model }\end{array}$} \\
\hline & $\begin{array}{l}\text { Zero } \\
\text { order }\end{array}$ & $1^{\text {st }}$ order & Peppas & Higuchi & & \\
\hline $\mathrm{F} 1$ & 0.9903 & 0.8011 & 0.9709 & 0.8009 & 1.7825 & Peppas \\
\hline $\mathrm{F} 2$ & 0.9792 & 0.8842 & 0.9915 & 0.8059 & 1.5856 & Peppas \\
\hline F3 & 0.9605 & 0.8696 & 0.9904 & 0.7502 & 1.8521 & Peppas \\
\hline $\mathrm{F} 4$ & 0.9798 & 0.8694 & 0.9898 & 0.8170 & 1.7254 & Peppas \\
\hline F5 & 0.9776 & 0.9093 & 0.9937 & 0.8157 & 1.6412 & Peppas \\
\hline F6 & 0.9768 & 0.7798 & 0.9872 & 0.8312 & 1.7427 & Peppas \\
\hline F7 & 0.9736 & 0.9072 & 0.9896 & 0.8081 & 1.6982 & Peppas \\
\hline F8 & 0.9737 & 0.9168 & 0.9886 & 0.8190 & 1.5695 & Peppas \\
\hline F9 & 0.9744 & 0.8815 & 0.9853 & 0.7745 & 1.5214 & Peppas \\
\hline
\end{tabular}

Table 9: Data of various parameters of model fitting for in vitro release of MTX loaded hydrogel NPs formulation.

best fit model was found Peppas model from the regression coefficients, this model was having more regression compared to all models. The " $\mathrm{n}$ " value for the formulation was 1.5 ; hence it was greater than 1 , which implies that release mechanism was assumed to be super case-II transport, wherein multiple release mechanism exists in drug release mechanism.

\section{Conclusion}

The results of the study indicated the PAAm-g-Gg polymer successfully synthesized by free radical polymerization from which hydrogel NPs are developed and release studies demonstrated that hydrogel NPs are capable of retarding the release of MTX until it reaches the colon, an environment rich in bacterial enzymes that degrade the Gum ghatti and allow drug release to occur at the desired site. Thus Gum ghatti hydrogel NPS are a potential system for colon delivery of MTX for chemotherapy of colon cancer.

\section{Reference}

1. Giovannucci E (2002) Epidemiologic studies of flote and colorectal neoplasia: a review. J Nutr 132: 2350S-2355S.

2. Giovannucci E (2004) Alcohol, one-carbon metabolism and colorectal cancer: recent insights from molecular studies. J Nutr 134: 2475S-2481S.

3. Ravi V, Promod KT, Siddaramaiah (2008) Novel colon delivery system using natural polymer. Ind J Pharm Sci 70: 111-113.

4. Basit A, Bloor J (2003) Perspectives on colonic drug delivery business briefing Pharmatech Pp:185-89.

5. Watts PJ, Illum L (1997) Colonic drug delivery. Drug Del \& Ind Pharm 29: 893913

6. Ray S, Benerjee S, Maiti S, Laha B, Barik S, et al. (2010) Novel interpenetratin network microspheres of xanthan gum-poly vinyl alcohol for the delivery of diclofenac sodium to the intestine in vitro and in vivo evaluation. Drug Del 17 508-519.

7. Arya RKK, Singh R, Juyal V (2010) Mucoadhesive microspheres of famotidine preparation characterization and in vitro evaluation. Int J Eng Sci Tech 2: 15751580.

8. Vandamme TF, Lenourry A, Charrueau C, Chaumeil JC (2002) The use of polysaccharides to target drugs to colon. Carbohydrate Polymers 48: 219-231.

9. Chourasia MK, Jain SK (2004) Polysaccharide for colon drug delivery. Drug Del 11: 129-148.

10. Reddy SM, Sinha VR, Reddy DS (1999) Novel oral colon specific drug delivery system for pharmacotherapy of peptide and nonpeptide drugs. Dtugs Today (Barc) 35: 537-580.

11. Goldstein AM, Alter EN, Seaman JK, Whistler RL (1993) Industrial gums, polysaccharides and their devivatives. New York, USA, Academic Press 303321.

12. Ramaprasad YV, Krishaniah YSR, Satyanarayana S (1999) Trends in colonic drug delivery: a review. Ind drugs. 
Citation: Kaur R, Gupta VK, Pandey SC (2019) Preparation and Evaluation of Hydrogel Nanoparticles as Drug Delivery System. J Nanomed Nanotechnol 10: 526. doi: 10.4172/2157-7439.1000526

13. Chourasia MK, Jain SK (2004) Potential of guar gum microspheres for target specific drug release to colon. J Drug Target 12: 435-442.

14. Davaran S, Rashidi MR, Pourabbas B, Dadashzadeh M, Haghshenas NM (2006) Adriamycin release from poly(lactide-co-glycolide)-polyethylene glyco nanoparticles: synthesis and in vitro characterization. Int J Nanomedicine 1: 535-539.
15. Seo DH, Jeong Y, Kim DG, Jang MJ, Jang MK, et al. (2009) Methotrexateincorporated polymeric nanoparticles of methoxy poly(ethylene glycol)-grafted chitosan. Colloids Surf B Biointerfaces 69: 157-163.

16. Dhanaraj SA, Muralidharan S, Santhi K, Hui ALS, Wen CJ, et al. (2014) Targeted drug delivery system- Formulation and evaluation of chitosan nanospheres containing Doxorubicin hydrochloride. Int J Drug Deliv 6: 186-193. 